\title{
Takotsubo Cardiomyopathy
}

National Cancer Institute

\section{Source}

National Cancer Institute. Takotsubo Cardiomyopathy. NCI Thesaurus. Code C85181.

A rare disorder characterized by transient left ventricular wall systolic dysfunction, resulting in apical ballooning appearance, chest pain, and ST segment elevation. 